\title{
Depictions of psychopathology and mental health issues in music: themes and musical genres.
}

\author{
Fabián A. Pavez R. ${ }^{1}$, Erika Saura P. ${ }^{2}$, Gemma Pérez Z. ${ }^{3}$, Pedro Marset C4.

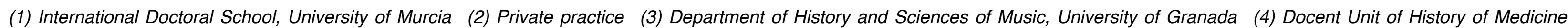 \\ University of Murcia
}

\section{Introduction.}

In previous communications we have proposed that the analysis of cultural products related to art, and music in particular, can inform us about the social representations of psychiatry and mental illness $(1,2)$.

\section{Objectives.}

By exploring studies addressing depictions of mental disorders or mental health concerns in music, we intend:

- to assess the distribution of psychopathological themes; and - to characterize the most studied musical genres that are associated to portrayals of mental disorders or mental health concerns.

\section{Method.}

Starting from a previous systematic review of studies addressing depictions of mental disorders or mental health issues in music, thirty-nine articles are examined (2). Frequency of portrayed themes and musical genres associated are presented.

\section{Findings.}

As we can expect, references to substance use in music are the most frequently studied. Studies addressing references to psychotic disorders in music are frequent too, but in a lesser extent (Figure 1). Other mental health issues depicted are: affective disorders; suicide-related behaviors; sexuality and gender; personality disorders; resilience; as well as general links between music and mental disorders/psychiatry.

Studies addressing substance use are mostly focused on multiple musical genres (based in popularity rankings). With regards substance use, Rap (3-5) and Rock (6-8) are two genres specifically studied. Links between country music, alcohol use and suicide have been described in literature (9).

\section{Figure 1. Distribution of Themes in Literature}

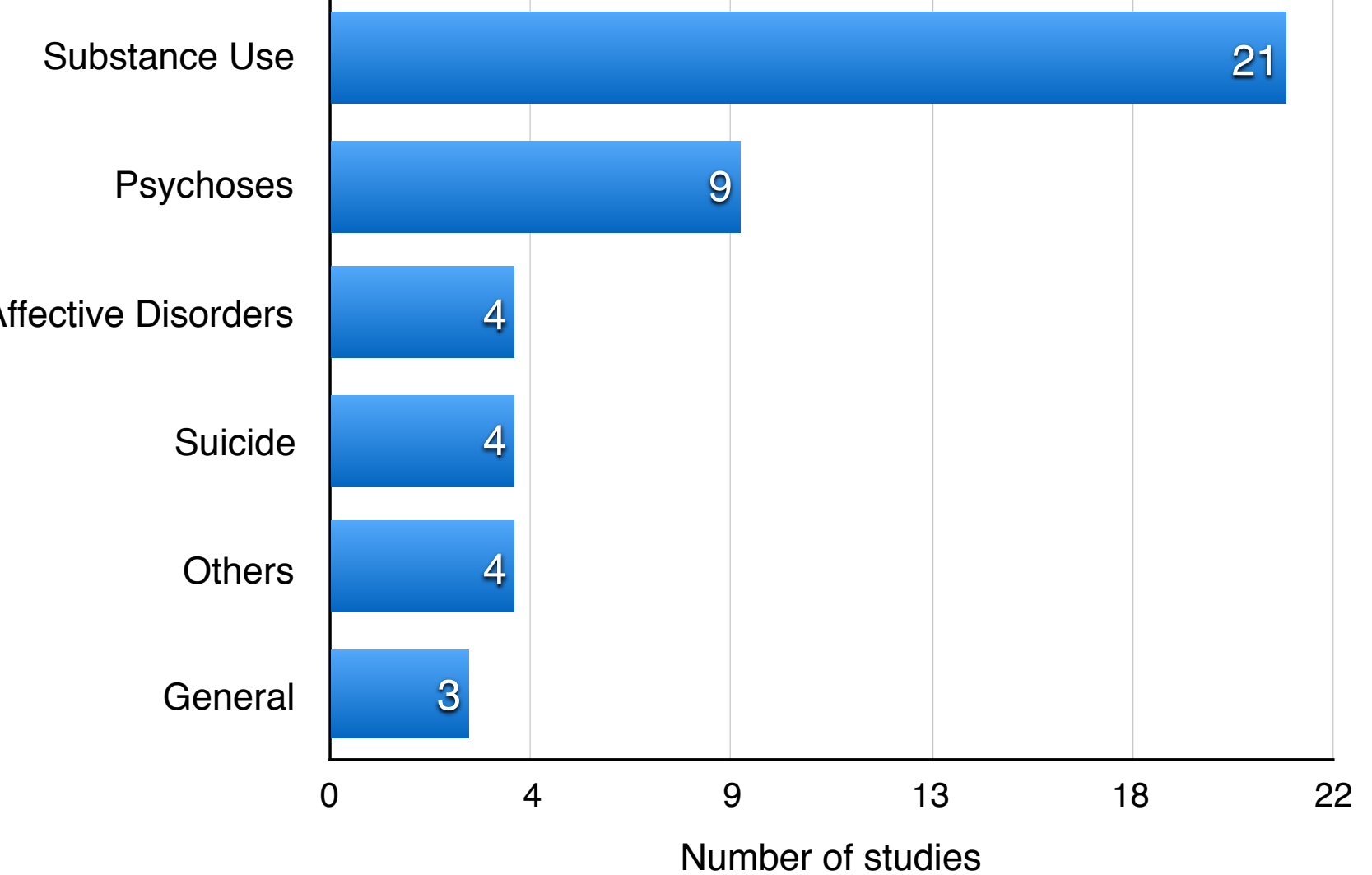

\section{WPA XVII WORLD CONGRESS} OF PSYCHIATRY
FIGURE 2. Distribution of themes by Musical Genre

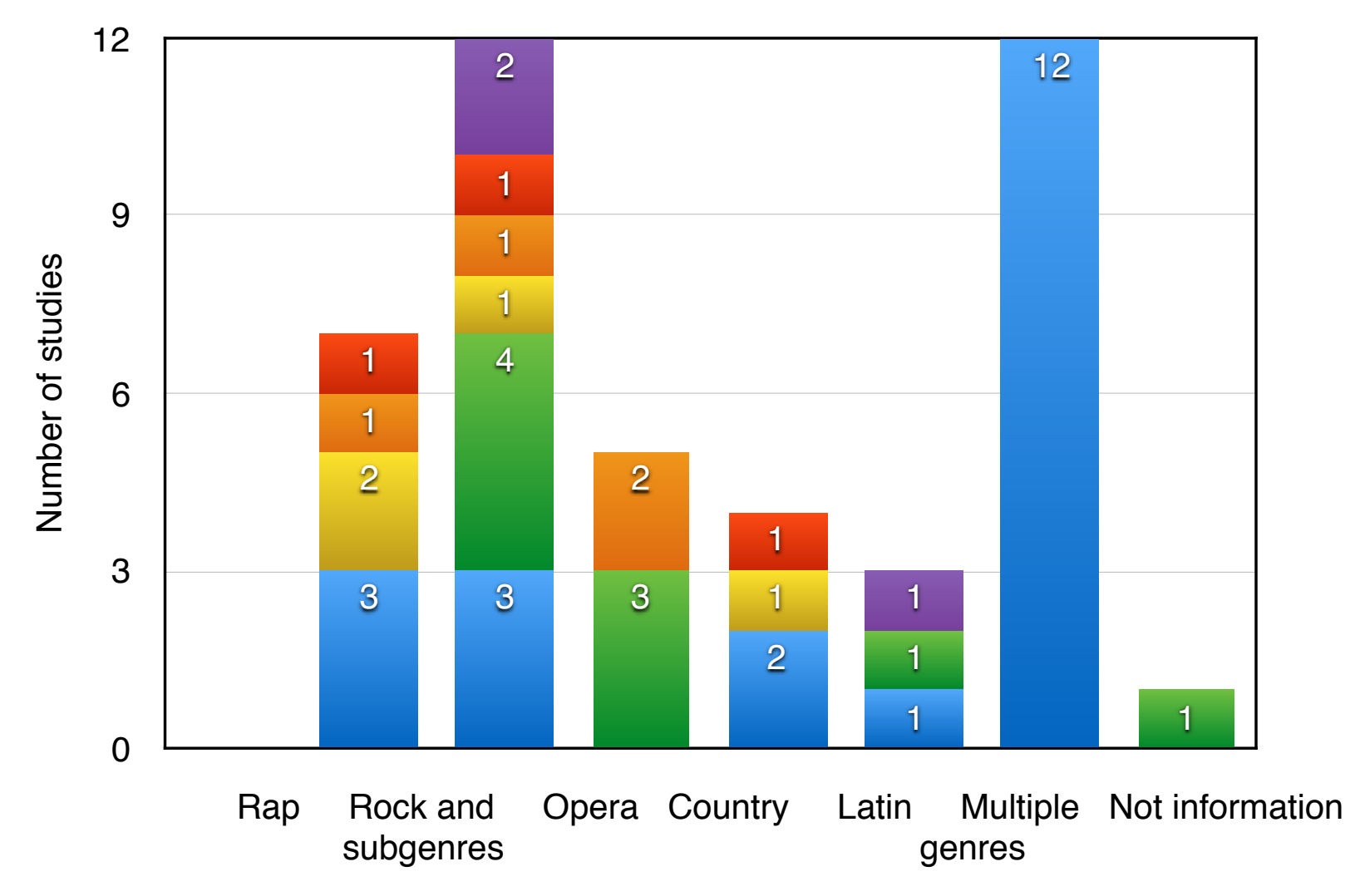

Substance Use - Affective Disorders

"Madness" / Psychoses

Other

Suicide

General

Rock and Opera are the genres more frequently associated with references to "madness". Studies focused on depictions of Suicide in Opera are present too. (Figure 2)

\section{Discussion.}

Psychiatry and Mental Disorders are represented in music. Most of literature addressing this issue is focused on the analysis of song lyrics. Substance use disorder was the most frequent theme (particularly, articles about exposition to substance use-related contents).

The analysis of representations of psychiatry and mental disorders in the popular culture is not irrelevant to our clinical practice. It favors a better understanding about what are the meanings (and misconceptions) of our profession (and mental suffering) for our patients and general population.

\section{References.}

1) Pavez F, Alcántara A, Saura E, Pérez G, Marset P. The Analysis of Music as a Cultural Product in Medicine and Psychiatry. In: 24th European Congress of Psychiatry. Madrid; 12-15 March 2016.

2) Pavez F, Saura E, Pérez G, Marset P. Social Representations of Psychiatry and Mental Illness Examined Through the Analysis of Music as a Cultural Product. Music and Medicine. 2017; in press.

3) Diamond S, Bermudez R, Schensul J. What's the Rap About Ecstasy?: Popular Music Lyrics and Drug Trends Among American Youth. J Adolesc Res. 2006; 21(3): 269-298.

4) Herd D. Changes in the prevalence of alcohol in rap music lyrics 1979-2009. Subst Use Misuse. 2014; 49(3): 333-342.

5) Sule A, Inkster B. Kendrick Lamar, street poet of mental health. The Lancet Psychiatry. 2015; 2(6): 496-497.

6) Oksanen A. Drinking to death: traditional masculinity, alcohol and shame in Finnish metal lyrics. Nord Stud Alcohol Drugs. 2011; 28(4): 357-371.

7) Woods G. Mother's Little Helper - psychiatry in music. Br J Psychiatry. 2016; 208(6): 555.

8) Conway KP, McGrain P. Understanding Substance Use and Addiction Through the Lyrics of Black Sabbath: A Content Analysis. Subst Use Misuse. 2016; 51(12): 1655-1663.

9) Connors GJ, Alpher VS. Alcohol themes within country-western songs. Int $J$ Addict. 1989; 24(5): 445-451. 